concludes with a section entitled "Problems and Clinical Correlation", with answers at the end of the book. These well-chosen questions orientate the student towards the key facts and reasoning of the preceding chapter. There is also a useful glossary of biochemical terms, and a very useful table of constituents of body fluids with their normal ranges.

Dr Frisell's book can be recommended to both medical and non-medical students, but they would probably prefer to find it in the library, rather than buy a personal copy.

In contrast, Paterson's Essentials of Human Biochemistry is small, reasonably priced and exciting. The description of biochemical pathways is totally integrated with the discussion of clinical disorders, amply illustrated with photographs and informative diagrams. No space is wasted in an economic juxtaposition of metabolic schemes, pictures and text, with the result that the book contains a surprising amount of information for its size. I was just a little disappointed in the chapter on hormones; there is insufficient stress on the central role of the pituitary, and I think the catechol oestrogens now deserve to be mentioned in teaching texts.

Dr Paterson has taken advice from a large number of experts in various areas of medical biochemistry, so that the text has an air of authority and is very up to date. This book can be strongly recommended for medical students and all biochemists with an interest in the medical aspects of their subject.

A senior colleague once jokingly suggested that the secret of impressive lecturing was to use an erudite text and not tell the students about it. Biochemistry for the Medical Sciences was surely the kind of book he had in mind. In this individualistic treatment of human biochemistry, structural and molecular aspects are excluded, and the approach is frankly metabolic. The usual pathways of intermediary metabolism are described and discussed in detail, and the treatment of energy metabolism and thermodynamics is particularly useful and is well geared to the general requirements of most students of medicine.

Above all, however, this book is characterized by its devotion to the integration of clinical physiology and biochemistry with a powerful emphasis on control and regulation. The tutor in search of a theme will be inspired by such titles as "Pathological changes in concentrations of lipid fuels" and "Metabolic responses to starvation", and by a delightful section on the comparative biochemistry of sprinting and marathon running. Within a rather novel framework the authors have produced a work of scholarship, which all lecturers should read and no student can afford to ignore.

Thomas A. Scott is Senior Lecturer in Biochemistry at the University of Leeds.

\section{Matters physical and chemical}

\section{E.G. Richards}

Physical Biochemistry: Applications to

Biochemistry and Molecular Biology, 2nd Edn.

By David Freifelder.

W.H. Freeman: 1982. Pp.761.

Hbk \$43.95; pbk \$24.95, £21.50.

Analytical Biochemistry.

By David J. Holme and Hazel Peck. Longman: 1983. Pp.480. £26, $\$ 57$.

THE physical methods used in biochemistry and molecular biology appear all too complicated to the student with little physics or mathematics, and one has come to expect such students to be daunted by books that deal with the principles of physical biochemistry in all their physical chemical detail. It is a rare textbook that does not have this effect. The second edition of Physical Biochemistry is one.

Freifelder has performed the notable service of bringing a large number of techniques and concepts within the comprehension of undergraduate and graduate students who are not primarily of a physical bent. While quite a number of useful formulae are scattered through the text, not many of them are derived and there is little mathematics. Instead, the emphasis is on qualitative and intuitive understanding. The text is lucid, the examples apposite and the diagrams up to the usual standards of W. H. Freeman. This book should help students to understand matters physical and help to dispel some of their mystery.

Physical biochemistry is defined liberally to include light and electron microscopy, immunological methods and DNA sequencing, as well as the more traditional techniques of ultracentrifugation, spectroscopy and fluorimetry - to mention but a few of an encyclopaedic range of topics covered (though there is nothing on crystallography). There are many detailed and illuminating analyses of real applications and each chapter includes a reading list and a set of problems (the answers being provided at the end of the book).

The original edition of this book was marred by a few unfortunate mistakes and some notable omissions. The mistakes have been corrected and the text expanded to include light-scattering techniques (among several other new subjects) and fuller descriptions of some topics already in the first edition. This second edition deserves to be popular with both students and their teachers. My only caveat is that graduate students will require something more meaty. The reading lists provided should set them on the right path to this.

It may be argued that chemical analysis is the sine qua non of serious biochemistry.
Certainly, specialized techniques are required, and in Analytical Biochemistry Holme and Peck have provided a useful compendium of such methods.

The book comes in three sections, in turn covering analytical methods, useful materials for analyses (enzymes, radioisotopes, antibodies), and the analysis of major groups of biologically important compounds (carbohydrates, amino acids, proteins and lipids - though, oddly, there is little on nucleic acids). The methods considered include spectroscopic, electroanalytical and immunological approaches in most of their various forms, as well as those which involve the use of radioisotopes and separation techniques. Both the theoretical background and the instrumentation involved are discussed succinctly, in adequate though not too exhaustive detail, and each chapter includes a list of further reading. The statistical aspects of the subject - perhaps given too little emphasis in some parts of the biochemical literature - are here properly discussed and duly emphasized.

It is useful, as the authors suggest, to have all these methods housed in one volume and Analytical Biochemistry will remain on my bookshelf as a source book. It deserves a similar fate with both undergraduate and graduate students.

E.G. Richards is a Senior Lecturer in the Department of Biophysics, King 's College, University of London.

MONOGRAPHS TEXTBOOKS...

and other technical publications on Nuclear Energy write for free publications and services catalog

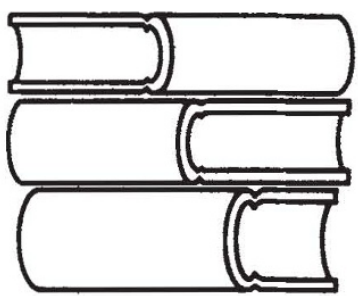

American Nuclear Society $555 \mathrm{~N}$. Kensington Ave. La Grange Park, IL 60525 (312) 352-6611

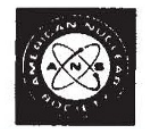

